\title{
Allied health and complementary therapy usage in Australian women with chronic pelvic pain: a cross-sectional study
}

\author{
Astha Malik ${ }^{1,2}$, Justin Sinclair ${ }^{2}$, Cecilia H. M. Ng ${ }^{3}$, Caroline A. Smith ${ }^{2,4}$, Jason Abbott ${ }^{3}$ and Mike Armour A $^{2,45^{*}}$ (i)
}

\begin{abstract}
Background: Chronic pelvic pain (CPP) causes non-cyclical pelvic pain, period pain, fatigue and other painful symptoms. Current medical and surgical management strategies are often not sufficient to manage these symptoms and may lead to uptake of other therapies.

Aims: To determine the prevalence of allied health $(\mathrm{AH})$ and complementary therapy $(\mathrm{CM})$ use, the cost burden of these therapies and explore predictive factors for using allied health or complementary medicines.

Materials and methods: An online cross-sectional questionnaire using the WERF EndoCost tool was undertaken between February to April 2017. People were eligible to participate in the survey if they were aged $18-45$, living in Australia and had chronic pelvic pain.

Results: From 409 responses, 340/409 (83\%) of respondents reported a diagnosis of endometriosis. One hundred and five (30\%) women with self-reported endometriosis, and thirteen (18\%) women with other forms of CPP saw at least one AH or CM practitioner in the previous two months, with physiotherapists and acupuncturists the most common. Women who accessed CM or AH services spent an average of $\$ 480.32$ AUD in the previous two months. A positive correlation was found between education and number of $\mathrm{AH}$ or $\mathrm{CM}$ therapies accessed in the past two months $(p<0.001)$ and between income level and number of therapists $(p=0.028)$.

Conclusions: Women with CPP commonly access AH and CM therapies, with a high out of pocket cost. The high cost and associations with income and education levels may warrant a change to policy to improve equitable access to these services.
\end{abstract}

Keywords: Complementary medicine, Allied health, Endometriosis, Pelvic pain, Cost of illness

\section{Introduction}

Chronic pelvic pain (CPP) can be broadly categorised as pain in the pelvic region that lasts longer than six months and requires medical attention [1]. Causes of CPP include endometriosis, adenomyosis, irritable bowel syndrome, adhesions and interstitial cystitis/painful

*Correspondence: m.armour@westernsydney.edu.au

${ }^{2}$ NICM Health Research Institute, Western Sydney University, Locked Bag

1797, Penrith, NSW 2751, Australia

Full list of author information is available at the end of the article bladder syndrome [2], amongst others [1]. Estimates for CPP prevalence varies across countries, with prevalence estimates ranging from 5.7 to $26.6 \%$ in women of reproductive age [3].

Management of CPP depends on the specific cause but broadly incorporates pain education, physical therapy, psychological therapy and various pharmacological and surgical interventions [4]. Endometriosis is a leading cause of CPP, affecting around 1 in 9 women in Australia by the age of 44 [5], and is commonly managed by analgesia and hormonal treatments or surgery [6]. People with

(c) The Author(s) 2022. Open Access This article is licensed under a Creative Commons Attribution 4.0 International License, which permits use, sharing, adaptation, distribution and reproduction in any medium or format, as long as you give appropriate credit to the original author(s) and the source, provide a link to the Creative Commons licence, and indicate if changes were made. The images or other third party material in this article are included in the article's Creative Commons licence, unless indicated otherwise in a credit line to the material. If material is not included in the article's Creative Commons licence and your intended use is not permitted by statutory regulation or exceeds the permitted use, you will need to obtain permission directly from the copyright holder. To view a copy of this licence, visit http://creativecommons.org/licenses/by/4.0/. The Creative Commons Public Domain Dedication waiver (http://creativeco mmons.org/publicdomain/zero/1.0/) applies to the data made available in this article, unless otherwise stated in a credit line to the data. 
endometriosis commonly report symptoms including dysmenorrhea, non-cyclical pelvic pain, dyspareunia, and fatigue [7]. Those with endometriosis report a significant economic burden [8], issues at work [9] and in education [7], poor mental health $[10,11]$ and the breakdown of sexual relationships [7]. All of this contributes to the reduced quality of life [12] reported by those with the disease.

Despite established management protocols, women with endometriosis often express frustration with medical treatment due to its inability to cure the disease, bothersome medication side effect profiles [13] and poor symptom management [14]. These may be contributing factors to why only half $(54.6 \%)$ of women with endometriosis are satisfied with their medical care [15].

Given the dissatisfaction with current medical management strategies, many women with CPP are using complementary medicine (CM) [16] and women with endometriosis are known to use both $\mathrm{CM}$ and allied health $(\mathrm{AH})$ services (including physiotherapy and psychology) to help manage their symptoms [14]. Under the Australian public healthcare system, people with chronic illness are entitled to subsidised $\mathrm{AH}$ treatment if they have a chronic disease management plan [17]. Although access to subsidised treatment may alleviate the burden of healthcare costs, a recent Australian study found only $15.4 \%$ of respondents had such a plan, despite eligibility due to endometriosis [14]. Therefore, there is likely to be substantial out of pocket costs for these CM and $\mathrm{AH}$ treatments. Given the already significant costs for women in Australia with CPP [8] and the strong relationship between greater pain levels and negative impact on work [8] and education, [18] ensuring that cost-effective treatment is both accessible and affordable is a priority.

Our study sought to determine which $\mathrm{CM}$ and $\mathrm{AH}$ modalities women with CPP were accessing, explore the cost burden of these, and determine any predictive factors for usage.

\section{Materials and methods}

This survey was approved by the Western Sydney University Human Research Ethics Committee, approval number H12019 (approved 21st January 2017). All research complied with the relevant guidelines and regulations outlined in the National Statement on Ethical Conduct in Human Research (2018) [19].

\section{Questionnaire}

The World Endometriosis Research Foundation (WERF) EndoCost tool consists of validated prospective hospital questionnaires and both retrospective and prospective patient questionnaires [20]. Our study used the 99 item retrospective patient questionnaire, modified to Australian income and ethnicity parameters as per the Australian Bureau of Statistics [21]. The survey was hosted on SurveyMonkey (www.surveymonkey.com), with an estimated 30-45-min completion time. This paper reports on data related to the use of $\mathrm{CM}$ and therapies (such as acupuncture and herbal medicine) and $\mathrm{AH}$ usage.

Two sections of the questionnaire covered $\mathrm{CM}$ and $\mathrm{AH}$ usage. All respondents were given the option to nominate up to five non-medical treatments used in the past two months. Respondents were advised that these treatments were not medical, surgical or related to monitoring but otherwise given a free text box to describe the category in their own words without restrictions.

\section{Recruitment}

Following ethics approval, the survey link was distributed via the social media platforms (Facebook, Twitter and Instagram) of Endometriosis Australia, EndoActive and the Pelvic Pain Foundation of Australia from February 2017 to April 2017, for a total of eight weeks. The total combined reach of these organizations on social media was just over 35,000 followers at the time of survey distribution. Each organization made two social media posts regarding the survey three to five weeks apart. Data collection was closed once there had been no new responses for five days. Informed consent was obtained from all respondents.

\section{Study population}

Women were eligible to participate in the survey if they were aged 18-45, currently living in Australia and had CPP. CPP was defined as pain in the pelvis for at least 6 months that caused the person to seek medical attention, regardless of the diagnosis, or lack thereof. This study was designed to measure prevalence and assess cost rather than test a hypothesis, therefore no sample size calculation was performed.

\section{Analyses}

Data were analysed using SPSS v26 (IBM Corporation, Chicago Ill.) and Excel v16 (Microsoft). Descriptive statistics were presented as means, weighted means and standard deviations (for normally distributed data), medians and interquartile ranges (for non-normally distributed data), or number and percentages (for categorical data). Inferential statistics for between-group comparisons were performed using a one-way ANOVA, chi-square test or Fishers Exact as appropriate. Correlations between categorical and continuous variables were analysed using Spearman's rank order correlation. Statistical significance was set at $p<0.05$. Missing data were reported and not replaced. 
Only numerical responses, or responses from which a number could be determined (e.g. listing therapies) were included. Respondents who could not recall a specific number were not counted as a response and a conservative approach was taken where respondents who listed " $\mathrm{n}+$ ", where $\mathrm{n}$ was a number, $\mathrm{n}$ was recorded as the number of therapists seen. $\mathrm{CM}$ and $\mathrm{AH}$ therapies were manually categorized and standardized by the first author (AM) (e.g., physiotherapy and physiotherapist were included in the same category) with guidance from the senior author (MA), who has expertise in $\mathrm{CM}$ and $\mathrm{AH}$. Responses which were clearly medical in nature, such as ultrasound, were not counted.

Cumulative costs were determined for each therapy, by summing the costs each respondent had recorded for the particular therapy. The cost per session was also determined by dividing the total cost by the number of sessions for each respondent. The mean and weighted mean cost per session was then calculated. Costs were only calculated for respondents with a valid total cost and number of sessions.

\section{Results}

Four hundred and nine valid responses were received. Three hundred and forty $(83.1 \%)$ respondents reported they had laparoscopically confirmed endometriosis (endometriosis cohort). Sixty-nine (16.9\%) respondents experienced CPP without a laparoscopically confirmed diagnosis of endometriosis (other CPP cohort). The mean age of respondents in the endometriosis cohort was 30.6 $( \pm 7)$ years and was $33.7( \pm 16.3)$ years in the other CPP cohort. Those in the other CPP cohort reported diagnoses that included no known cause/diagnosis for CPP (40.6\%), been told by their doctor they had endometriosis but no visual confirmation (43.5\%), adenomyosis (10.1\%) and ovarian cysts $(5.8 \%)$. Table 1 outlines the demographics of the respondents.

\section{Overall $\mathrm{AH}$ and complementary therapy usage}

One hundred and forty-three (42.1\%) women with endometriosis reported seeing at least one $\mathrm{AH}$ or complementary therapist prior to their diagnosis. Thirty-five $(24.5 \%)$ women reported seeing one therapist, 50 (35.0\%) reported seeing two, 21 (14.7\%) reported seeing three, 12 (8.4\%) reported seeing four and $25(17.5 \%)$ reported seeing five or more therapists.

One hundred and five (30.9\%) women in the endometriosis cohort and 13 women in the other CPP cohort (18.8\%) saw at least one $\mathrm{AH}$ or complementary therapist in the two months preceding the survey. Of the 105 women in the endometriosis cohort who had seen a therapist in the previous two months, the majority (60.0\%), reported seeing one therapist and one-third (31.4\%) reported two therapists. Of the 13 women in the other CPP cohort who had seen a therapist in the previous two months, almost half (46.2\%) had seen one therapist and one-third (30.8\%) reported seeing two therapists.

\section{Access to $\mathrm{AH}$ and $\mathrm{CM}$ health care providers}

The most commonly accessed $\mathrm{AH}$ and complementary therapists by those in the endometriosis cohort were physiotherapists (11.5\%), mental health workers (e.g., psychologists, psychotherapist, counsellor) (6.5\%), massage therapists $(5.6 \%)$ and acupuncturists (5.6\%). The other CPP cohort reported physiotherapists (7.3\%), naturopaths (5.8\%), acupuncturists (4.4\%) and nutritionist/dietitians (4.4\%) as the most common therapists consulted.

Table 2 outlines the types of $\mathrm{AH}$ and complementary therapists consulted by respondents.

\section{Cost to women from consulting the health care provider}

Across the two cohorts, women had cumulatively spent a total of $\$ 53,315$ on $\mathrm{AH}$ and complementary therapists in the two months preceding the survey, across 530 sessions, and 111 respondents with at least one valid response regarding costs and sessions; endometriosis $(\mathrm{n}=99)$, other CPP $(\mathrm{n}=12)$. Women who accessed CM or AH services spent an average of $\$ 480.32$. Women in the endometriosis cohort, on average spent a total of $\$ 460.04$, compared to women in the other CPP cohort who spent $\$ 647.58$. Figure 1 outlines the cumulative cost per therapy in each cohort.

Women in the endometriosis cohort spent the most money on physiotherapists $(\$ 10,525)$, followed by mental health workers (\$7555), naturopaths (\$7320) and acupuncturists (\$6587). Women in the other CPP cohort spent the most money on mental health workers (\$1950), followed by physiotherapists (\$1215), Clinical Pilates therapists (\$1000) and acupuncturists (\$900).

Total expenditure across the two cohorts was highest for physiotherapists $(\$ 11,740)$, followed by mental health workers (\$9505), naturopaths (\$7936) and acupuncturists (\$7487). The lowest expenditure was on reflexologists with a total of $\$ 80$ across the two cohorts.

Excluding therapists with only one respondent, naturopaths had the highest cost per session (\$187.65), followed by nutritionist/dietitians (\$131.07), mental health workers (\$127.27) and acupuncturists (\$87.83). Figure 2 outlines the weighted mean cost per session per therapist with data from both cohorts.

\section{Predictive factors for AH/CM usage}

A statistically significant positive correlation was found between education levels and number of $\mathrm{AH}$ 
Table 1 Demographic characteristics of respondents

\begin{tabular}{|c|c|c|}
\hline & $\begin{array}{l}\text { Self-reported endometriosis }(n=340) \\
\text { Mean (SD) }\end{array}$ & $\begin{array}{l}\text { Other CPP }(n=69) \\
\text { Mean }(S D)\end{array}$ \\
\hline Age (years) & $30.6(7.0)$ & $33.7(16.3)$ \\
\hline \multicolumn{3}{|l|}{ Ethnicity, n (\%) } \\
\hline Caucasian & $312(91.8 \%)$ & $64(92.8 \%)$ \\
\hline Asian & $5(1.5 \%)$ & $2(2.9 \%)$ \\
\hline Aboriginal and/or Torres Strait Islander & $5(1.5 \%)$ & $1(1.4 \%)$ \\
\hline Other & $17(5 \%)$ & $2(2.8 \%)$ \\
\hline \multicolumn{3}{|l|}{ Relationship status, $\mathrm{n}(\%)$} \\
\hline Single & $69(20.3 \%)$ & $14(20.3 \%)$ \\
\hline Married/defacto & $211(62.1 \%)$ & $50(72.5 \%)$ \\
\hline In a relationship but not living with partner & $49(14.4 \%)$ & $4(5.8)$ \\
\hline Divorced/separated & $9(2.6 \%)$ & $0(0 \%)$ \\
\hline Widowed & $0(0 \%)$ & $1(1.4 \%)$ \\
\hline Blank & $2(0.6 \%)$ & $0(0 \%)$ \\
\hline \multicolumn{3}{|l|}{ Occupation, n (\%) } \\
\hline Self-employed & $23(6.8 \%)$ & $4(5.8 \%)$ \\
\hline Employed & $236(69.4 \%)$ & $47(68.1 \%)$ \\
\hline Attending school or university & $70(20.6 \%)$ & $15(21.7 \%)$ \\
\hline Home duties/caring for children and family & $43(12.6 \%)$ & $10(14.5 \%)$ \\
\hline Doing voluntary work & $18(5.3 \%)$ & $2(2.9 \%)$ \\
\hline Unable to work due to pelvic pain symptoms & $23(6.8 \%)$ & $7(10.1 \%)$ \\
\hline Unable to work for other reasons & $5(1.5 \%)$ & $2(2.9 \%)$ \\
\hline \multicolumn{3}{|l|}{ Level of education, $n$ (\%) } \\
\hline Primary school & $0(0 \%)$ & $0(0 \%)$ \\
\hline Lower secondary & $24(7 \%)$ & $2(2.9 \%)$ \\
\hline Upper secondary & $47(13.8 \%)$ & $6(8.7 \%)$ \\
\hline Post-secondary (TAFE) ${ }^{\mathrm{a}}$ & $91(26.8 \%)$ & $22(31.9 \%)$ \\
\hline University & $123(36.2 \%)$ & $25(36.2 \%)$ \\
\hline Post graduate & $55(16.2 \%)$ & $14(20.3 \%)$ \\
\hline \multicolumn{3}{|l|}{ Currently have children, $\mathrm{n}(\%)$} \\
\hline Yes & $97(28.5 \%)$ & $23(33.3 \%)$ \\
\hline No & $242(71.2 \%)$ & $46(66.7 \%)$ \\
\hline Blank & $1(<1 \%)$ & $0(0 \%)$ \\
\hline \multicolumn{3}{|c|}{ rAFS/ASRM stage at most recent laparoscopy, $n$ (\%) } \\
\hline Stage 1 & $14(4.1 \%)$ & \\
\hline Stage 2 & $51(15 \%)$ & \\
\hline Stage 3 & 75 (22.1\%) & \\
\hline Stage 4 & 115 (33.7\%) & \\
\hline Can't remember & $57(16.8 \%)$ & \\
\hline Blank & $28(8.3 \%)$ & \\
\hline
\end{tabular}

${ }^{a}$ Technical and Further Education (TAFE) is an Australian vocational education and training provider

or complementary therapists accessed in the past two months when looking at combined data for both cohorts, $\mathrm{r}_{\mathrm{s}}=0.204 \quad(p<0.001)$. A statistically significant positive correlation was found between income levels and number of therapists accessed when looking at combined data for both cohorts, $\mathrm{r}_{\mathrm{s}}=0.108(p=0.028)$. 
Table 2 CM and AH health care providers seen by women with endometriosis and CPP

\begin{tabular}{|c|c|c|c|c|}
\hline \multirow[t]{2}{*}{ Therapist/health care provider } & \multirow{2}{*}{$\begin{array}{l}\text { Self-reported } \\
\text { endometriosis } n(\%)\end{array}$} & \multirow[t]{2}{*}{ Other CPP n (\%) } & \multicolumn{2}{|l|}{ Both cohorts $^{\ddagger}$} \\
\hline & & & $\begin{array}{l}\mathrm{n} \text { (\% of total } \\
\text { respondents) }\end{array}$ & $\begin{array}{l}\% \text { of } \\
\text { therapy } \\
\text { users }^{\dagger}\end{array}$ \\
\hline Physiotherapist & $39(37.1 \%)$ & $5(38.5 \%)$ & $44(10.8 \%)$ & $37.3 \%$ \\
\hline Mental health worker & $22(21.0 \%)$ & $2(15.4 \%)$ & $24(5.9 \%)$ & $20.3 \%$ \\
\hline Acupuncturist & $19(18.1 \%)$ & $3(23.1 \%)$ & $22(5.4 \%)$ & $18.6 \%$ \\
\hline Massage therapist & $19(18.1 \%)$ & $2(15.4 \%)$ & $21(5.1 \%)$ & $17.8 \%$ \\
\hline Naturopath & $17(16.2 \%)$ & $4(30.8 \%)$ & $21(5.1 \%)$ & $17.8 \%$ \\
\hline Nutritionist/dietitian & $11(10.5 \%)$ & $3(23.1 \%)$ & $14(3.4 \%)$ & $11.9 \%$ \\
\hline Chiropractor & $11(10.5 \%)$ & $1(7.7 \%)$ & $12(2.9 \%)$ & $10.2 \%$ \\
\hline Osteopath & $8(7.6 \%)$ & $1(7.7 \%)$ & $9(2.2 \%)$ & $7.6 \%$ \\
\hline Supplements (unknown provider) & $5(4.8 \%)$ & $0(0.0 \%)$ & $5(1.2 \%)$ & $4.2 \%$ \\
\hline Reflexologist & $2(1.9 \%)$ & $0(0.0 \%)$ & $2(0.5 \%)$ & $1.7 \%$ \\
\hline Clinical pilates therapist & $0(0.0 \%)$ & $1(7.7 \%)$ & $1(0.2 \%)$ & $0.8 \%$ \\
\hline Emmett treatment & $1(0.9 \%)$ & $0(0.0 \%)$ & $1(0.2 \%)$ & $0.8 \%$ \\
\hline Endo diet & $1(0.9 \%)$ & $0(0.0 \%)$ & $1(0.2 \%)$ & $0.8 \%$ \\
\hline Herbalist $^{\S}$ & $1(0.9 \%)$ & $0(0.0 \%)$ & $1(0.2 \%)$ & $0.8 \%$ \\
\hline Homeopath & $1(0.9 \%)$ & $0(0.0 \%)$ & $1(0.2 \%)$ & $0.8 \%$ \\
\hline Integrated medicine doctor ${ }^{\S}$ & $1(0.9 \%)$ & $0(0.0 \%)$ & $1(0.2 \%)$ & $0.8 \%$ \\
\hline Meditation & $1(0.9 \%)$ & $0(0.0 \%)$ & $1(0.2 \%)$ & $0.8 \%$ \\
\hline Pelvic floor specialist ${ }^{\S}$ & $1(0.9 \%)$ & $0(0.0 \%)$ & $1(0.2 \%)$ & $0.8 \%$ \\
\hline \multirow[t]{2}{*}{ Sexologist } & $0(0.0 \%)$ & $1(7.7 \%)$ & $1(0.2 \%)$ & $0.8 \%$ \\
\hline & 160 & 23 & 183 & \\
\hline
\end{tabular}

${ }^{\dagger}$ Percentages may add to over $100 \%$ as they are calculated as a percentage of the number of respondents who reported using a therapy

${ }^{\ddagger}$ In the total column, percentages are expressed as a proportion of total number of respondents $(n=409)$ and total number of respondents who use therapies ( $n=118$ )

${ }^{\S}$ Note for these therapists, the name of the therapists reflects the respondents' description

\section{Discussion}

Our study found that usage of $\mathrm{CM}$ or $\mathrm{AH}$ therapists was common amongst all those with CPP, irrespective of diagnosis. The use of complementary therapies is similar to other usage estimates found in Australian women with endometriosis (42.9\%) [14] and higher than prevalence estimates of the general Australian population (36.0\%) [22]. These high rates of usage are not unexpected given that predictive factors for $\mathrm{CM}$ usage are being female, $<65$ years old, well-educated and with chronic, unresolved health problems[23].

Women with endometriosis are often dissatisfied with medical treatments due to side effect profiles and unsatisfying interactions with medical staff [24]. These factors may lead to women with endometriosis feeling disempowered in the medical system. As such, patients may choose to see CM or AH practitioners, to increase feelings of empowerment [25]. Many doctors have expressed frustration with a lack of treatment options to offer women with endometriosis [26] and for not receiving adequate training in dealing with the complex psychosocial issues involved in CPP [27]. These factors may contribute to why women often report feeling dismissed or their pain experience minimised when visiting their doctor [28], and why they may choose to seek out CM or AH care despite the additional cost.

Differences in the prevalence of use of various CM and $\mathrm{AH}$ modalities in our respondents may have a number of contributing factors. Allied health practitioners such as physiotherapists may have higher usage due to the Chronic Disease Management program in Australia which grants patients access to five subsidised $\mathrm{AH}$ sessions per year [29] but does not provide this for CM services. Previous studies have shown that less than one in five women with endometriosis in Australia actually have a chronic disease management plan [14] and therefore it's unclear how much of a contributor this would be to differences in $\mathrm{AH}$ vs CM usage.

Despite their popularity, there is limited high-quality evidence for each therapy accessed, including physiotherapy/physical therapy techniques such as pelvic floor muscle down-training[30], acupuncture [31] and psychological therapies [32]. There is no current research on naturopathy as a whole systems therapy but 


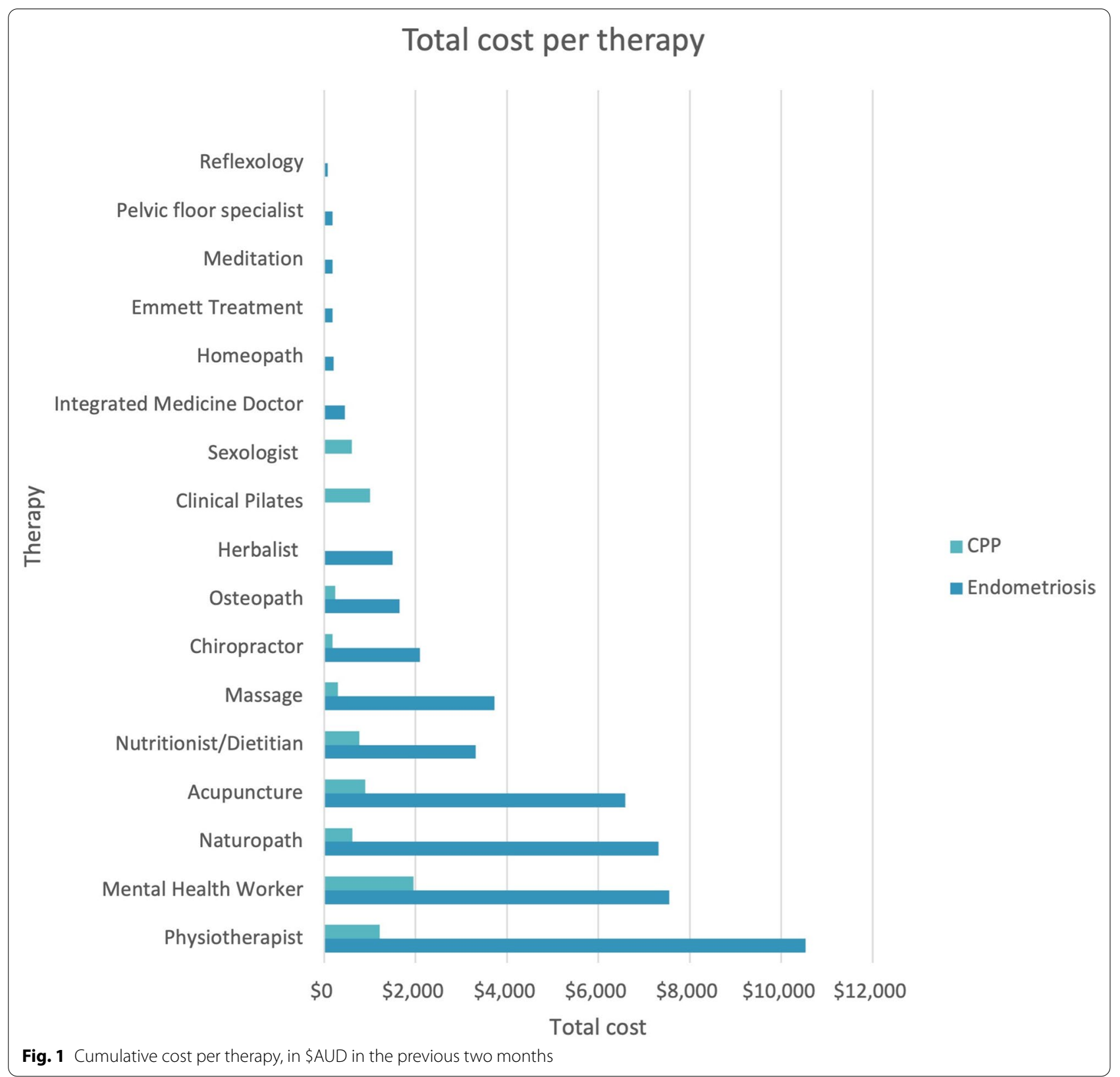

some evidence to suggest that supplements such as palmitoylethanolamide (PEA) that may be prescribed by a naturopath could be useful in managing pain [33]. Considering the popularity of these therapies within our cohort, as well as the significant cost burden associated, resources should be allocated into exploring the effectiveness of these therapies. In Australia, the National Action Plan for Endometriosis [34] acknowledges that endometriosis research into allied health and complementary therapies should be prioritised. Our research suggests five key areas could be prioritised based on current usage: physiotherapy, psychology, acupuncture, massage and naturopathy.

Previous research has shown that the symptom presentation, and cost burden for chronic pelvic pain is similar, irrespective of the underlying cause $[7,8]$. However it is important to note that while it seems that pelvic pain severity, rather than the cause of that pain, is a key factor in the reduced quality of life seen [35], an accurate differential diagnosis of the cause of certain symptoms is still vital for effective treatment. Some symptoms, such as dyspareunia and pelvic floor dysfunction can be caused by several underlying CPP conditions including 


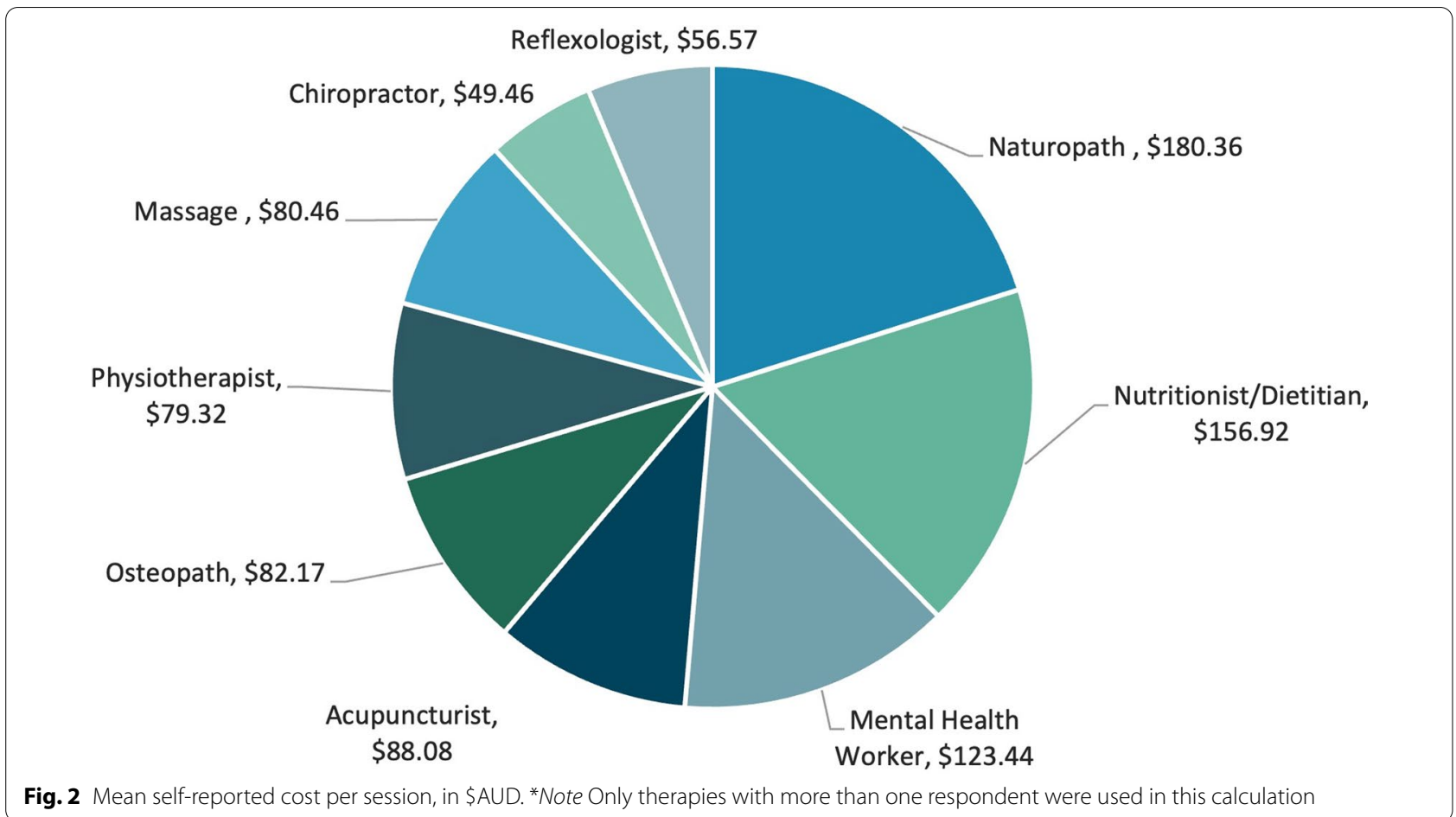

vulvodynia and deep infiltrating endometriosis, the latter of which may require surgery rather than pelvic physiotherapy alone [36]. Likewise, painful bladder syndrome/ interstitial cystitis has a significant symptom overlap with endometriosis and vulvodynia [37], and indeed endometriosis and painful bladder syndrome are commonly found together [37, 38], however symptom management may differ based on the underlying cause [2].

Our study found an association between increasing income and education levels and greater AH/CM therapy usage, consistent with other studies which found that education levels are positively correlated with complementary therapy usage [39]. There is conflicting evidence about whether income is associated with CM usage, however most studies report there is either a positive relationship or no relationship [40]. This suggests there may be equity and accessibility issues for patients with lower levels of education and/or income.

In Australia, the Australian government acknowledges increasing accessibility to $\mathrm{CM}$ therapies as a priority in the National Action Plan for Endometriosis, but no such guidance exists for those with CPP from other causes. These significant rates of CM therapy usage in managing chronic pelvic pain are not specific to Australia [41, 42] and therefore given the significant out of pocket costs associated with endometriosis in other countries [43], it is likely that issues of cost and accessibility are present across a wide variety of geographical locations.

\section{Strengths and limitations}

The main strengths of our study are that the results are consistent with the literature, there is a diverse range of respondents, and it uses the EndoCost tool which provides a large amount of comparable data. However, there are some important limitations that need to be outlined. Firstly, responses were self-reported and due to the anonymous nature of the survey no confirmation of diagnosis could be sought. However, a self-reported diagnosis of endometriosis is accurate in most cases [44]. Secondly, information about private health insurance was not collected. This may confound results as having private health insurance with extra cover has been shown to be associated with CM usage in Australian women with endometriosis [14] and therefore it is unclear if the costs found reflect a full fee or out-of-pocket cost. Thirdly, because we allowed participants to enter the therapists they saw in their own words where we were unsure how these should be categorised, we left these separate, as in the case of 'pelvic floor specialist' and 'sexologist'. It is possible that these would fall under pelvic physiotherapist and mental health workers respectively, but we report them separately for transparency. Finally, our sample had a high proportion of Caucasian respondents, which may have influenced the prevalence as there is some evidence to suggest CM usage is higher in Caucasian populations [40]. 


\section{Conclusion}

Our study found that women with CPP, regardless of cause, have high rates of $\mathrm{CM}$ and $\mathrm{AH}$ usage, associated with a high cost to patients. Common therapies accessed within this population include physiotherapy, mental health care, acupuncture, massage therapy and naturopathy. Key drivers for seeking out CM or AH may be lack of effective medical treatment options or side effects. There was a positive association between usage of CM and/or AH and education and income levels. Given the high rate of usage, further research into the efficacy of specific treatments may be warranted. Moreover, the high cost and associations with income and education levels may warrant a change to policy to improve equitable access to these services.

\section{Acknowledgements}

Thank you to all the endometriosis organisations who distributed this survey including Endometriosis Australia, EndoActive and the Pelvic Pain Foundation of Australia. Thank you to the World Endometriosis Research Federation (WERF) for providing the EndoCost tool.

\section{Authors' contributions}

Conceived and designed the study MA, CS, JA Data collection MA. Data analysis AM, MA. Project supervision MA. Contributed to writing the manuscript; Original draft AM, MA, JS. Review and editing MA, AM, JS, CN, JA, CS. All authors read and approved the final manuscript.

\section{Disclaimers}

The views, opinions, findings, and conclusions or recommendations expressed in this PAPER are strictly those of the AUTHOR(s).

\section{Funding}

No external funding was provided. AM was funded by an internal Western Sydney University Summer Scholarship.

\section{Availability of data and materials}

The datasets used and/or analyzed during the current study are not publicly available due to ethical restrictions available from the corresponding author on reasonable request.

\section{Declarations}

\section{Ethics approval and informed consent}

Ethical approval was obtained from Western Sydney University Human Ethics Committee $\mathrm{H} 12019$ (approved $21^{\text {st }}$ January 2017). All research complied with the relevant guidelines and regulations outlined in the National Statement on Ethical Conduct in Human Research (2018). Informed consent was gained prior to participants completing the survey.

\section{Consent for publication}

Not applicable.

\section{Competing interests}

AM, JS, CS, MA are part of NICM Health Research Institute. As a medical research institute, NICM receives research grants and donations from foundations, universities, government agencies, individuals and industry. Sponsors and donors provide untied funding for work to advance the vision and mission of the Institute. The project that is the subject of this article was not undertaken as part of a contractual relationship with any organization other than the funding declared in the Acknowledgements. It should also be noted that NICM Health Research Institute conducts clinical trials relevant to this topic area, for which further details can be provided on request. MA is a clinical advisory board member for Endometriosis Australia. JA is the medical director for Endometriosis Australia. CN reports nothing to declare.

\section{Author details}

${ }^{1}$ School of Medicine, Western Sydney University, Penrith, NSW 2751, Australia. ${ }^{2}$ NICM Health Research Institute, Western Sydney University, Locked Bag 1797, Penrith, NSW 2751, Australia. 'S School of Women's and Children's Health, University of New South Wales, Sydney, NSW, Australia. ${ }^{4}$ Translational Health Research Institute, Western Sydney University, Penrith, NSW 2751, Australia.

${ }^{5}$ Medical Research Institute of New Zealand (MRINZ), Wellington, New Zealand.

Received: 13 December 2021 Accepted: 31 January 2022

Published online: 11 February 2022

\section{References}

1. Daniels JP, Khan KS. Chronic pelvic pain in women. BMJ. 2010;341:C4834.

2. Patnaik SS, Laganà AS, Vitale SG, Butticè S, Noventa M, Gizzo S, Valenti G, Rapisarda AMC, La Rosa VL, Magno C, et al. Etiology, pathophysiology and biomarkers of interstitial cystitis/painful bladder syndrome. Arch Gynecol Obstet. 2017;295(6):1341-59.

3. Ahangari A. Prevalence of chronic pelvic pain among women: an updated review. Pain Physician. 2014;17(2):E141-147.

4. EAU Guidelines on Chronic Pelvic Pain. https://uroweb.org/wp-content/ uploads/EAU-Guidelines-on-Chronic-Pelvic-Pain-2020.pdf.

5. Rowlands IJ, Abbott JA, Montgomery GW, Hockey R, Rogers P, Mishra GD. Prevalence and incidence of endometriosis in Australian women: a data linkage cohort study. BJOG. 2021;128(4):657-65.

6. Chapron C, Marcellin L, Borghese B, Santulli P. Rethinking mechanisms, diagnosis and management of endometriosis. Nat Rev Endocrinol. 2019;15(11):666-82.

7. Armour M, Sinclair J, Ng CHM, Hyman MS, Lawson K, Smith CA, Abbott J. Endometriosis and chronic pelvic pain have similar impact on women, but time to diagnosis is decreasing: an Australian survey. Sci Rep. 2020;10(1):16253.

8. Armour M, Lawson K, Wood A, Smith CA, Abbott J. The cost of illness and economic burden of endometriosis and chronic pelvic pain in Australia: a national online survey. PLoS ONE. 2019;14(10):e0223316.

9. Armour M, Ciccia D, Stoikos C, Wardle J. Endometriosis and the workplace: lessons from Australia's response to COVID-19. Aust N Z J Obstet Gynaecol. 2021. https://doi.org/10.1111/ajo.13458.

10. Laganà AS, Condemi I, Retto G, Muscatello MR, Bruno A, Zoccali RA, Triolo $\mathrm{O}$, Cedro C. Analysis of psychopathological comorbidity behind the common symptoms and signs of endometriosis. Eur J Obstet Gynecol Reprod Biol. 2015:194:30-3.

11. Laganà AS, La Rosa VL, Rapisarda AMC, Valenti G, Sapia F, Chiofalo B, Rossetti D, Ban Frangež H, Vrtačnik Bokal E, Vitale SG. Anxiety and depression in patients with endometriosis: impact and management challenges. Int J Womens Health. 2017;9:323-30.

12. D'Alterio MN, Saponara S, Agus M, Laganà AS, Noventa M, Loi ES, Feki A, Angioni S. Medical and surgical interventions to improve the quality of life for endometriosis patients: a systematic review. Gynecol Surg. 2021;18(1):13.

13. Rowe HJ, Hammarberg K, Dwyer S, Camilleri R, Fisher JRW. Improving clinical care for women with endometriosis: qualitative analysis of women's and health professionals' views. J Psychosom Obstet Gynecol. 2019;42:174-80.

14. O'Hara R, Rowe H, Fisher J. Managing endometriosis: a cross-sectional survey of women in Australia. J Psychosom Obstet Gynaecol. 2020.https:// doi.org/10.1080/0167482X.2020.1825374

15. Lukas I, Kohl-Schwartz A, Geraedts K, Rauchfuss M, Wölfler MM, Häberlin F, von Stephanie O, Eberhard M, Imthurn B, Imesch P, et al. Satisfaction with medical support in women with endometriosis. PLOS ONE. 2018;13(11):e0208023.

16. Fisher C, Adams J, Hickman L, Sibbritt D. The use of complementary and alternative medicine by 7427 Australian women with cyclic perimenstrual pain and discomfort: a cross-sectional study. BMC Complement Altern Med. 2016;16:129.

17. Chronic Disease Management (formerly Enhanced Primary Care or EPC). https://www1.health.gov.au/internet/main/publishing.nsf/Content/ mbsprimarycare-chronicdiseasemanagement. 
18. Armour M, Ferfolja T, Curry C, Hyman MS, Parry K, Chalmers KJ, Smith CA, MacMillan F, Holmes K. The prevalence and educational impact of pelvic and menstrual pain in Australia: A national online survey of 4202 young women aged 13-25 years. J Pediatr Adolesc Gynecol. 2020;33(5):511-8.

19. National Statement on Ethical Conduct in Human Research 2007 (Updated 2018). www.nhmrc.gov.au/guidelines/publications/e72.

20. Simoens S, Hummelshoj L, Dunselman G, Brandes I, Dirksen C, D'Hooghe T, EndoCost C. Endometriosis cost assessment (the EndoCost study): a cost-of-illness study protocol. Gynecol Obstet Invest. 2011;71(3):170-6.

21. 1249.0 - Australian Standard Classification of Cultural and Ethnic Groups (ASCCEG). http://www.abs.gov.au/ausstats/abs@.nsf/mf/1249.0.

22. Steel A, Mclntyre E, Harnett J, Foley H, Adams J, Sibbritt D, Wardle J, Frawley J. Complementary medicine use in the Australian population: results of a nationally-representative cross-sectional survey. Sci Rep. 2018;8(1):17325.

23. Pledger MJ, Cumming JN, Burnette M. Health service use amongst users of complementary and alternative medicine. N Z Med J. 2010;123(1312):26-35.

24. Young K, Fisher J, Kirkman M. Women's experiences of endometriosis: a systematic review and synthesis of qualitative research. J Fam Plan Reprod Health Care. 2015;41(3):225.

25. Roomaney R, Kagee A. Coping strategies employed by women with endometriosis in a public health-care setting. J Health Psychol. 2015;21(10):2259-68.

26. Grundström H, Kjølhede P, Berterö C, Alehagen S. "A challenge" —healthcare professionals' experiences when meeting women with symptoms that might indicate endometriosis. Sex Reprod Healthc. 2016;7:65-9.

27. Young K, Fisher J, Kirkman M. Clinicians' perceptions of women's experiences of endometriosis and of psychosocial care for endometriosis. Aust N Z J Obstet Gynaecol. 2017;57(1):87-92.

28. Young K, Fisher J, Kirkman M. Women's experiences of endometriosis: a systematic review and synthesis of qualitative research. J Fam Plan Reprod Health Care. 2015:41(3):225-34.

29. Cant RP, Foster MM. Investing in big ideas: utilisation and cost of Medicare Allied Health services in Australia under the Chronic Disease Management initiative in primary care. Aust Health Rev. 2011;35(4):468-74.

30. Fuentes-Márquez P, Cabrera-Martos I, Valenza MC. Physiotherapy interventions for patients with chronic pelvic pain: a systematic review of the literature. Physiother Theory Pract. 2019;35(12):1131-8.

31. Lund I, Lundeberg T. Is acupuncture effective in the treatment of pain in endometriosis? J Pain Res. 2016;9:157-65.

32. Hansen KE, Kesmodel US, Kold M, Forman A. Long-term effects of mindfulness-based psychological intervention for coping with pain in endometriosis: a six-year follow-up on a pilot study. Nordic Psychol. 2017;69(2):100-9.

33. Huijs E, Nap A. The effects of nutrients on symptoms in women with endometriosis: a systematic review. Reprod Biomed Online. 2020;41(2):317-28.

34. National Action Plan for Endometriosis. http://www.health.gov.au/inter net/main/publishing.nsf/Content/endometriosis.

35. Facchin F, Barbara G, Saita E, Mosconi P, Roberto A, Fedele L, Vercellini P. Impact of endometriosis on quality of life and mental health: pelvic pain makes the difference. J Psychosom Obstet Gynecol. 2015;36(4):135-41.

36. Di Donato N, Montanari G, Benfenati A, Monti G, Leonardi D, Bertoldo V, Facchini C, Raimondo D, Villa G, Seracchioli R. Sexual function in women undergoing surgery for deep infiltrating endometriosis: a comparison with healthy women. J Fam Plan Reprod Health Care. 2015;41(4):278-83.

37. Cervigni M, Natale F. Gynecological disorders in bladder pain syndrome/ interstitial cystitis patients. Int J Urol. 2014;21(Suppl 1):85-8.

38. Tirlapur SA, Kuhrt K, Chaliha C, Ball E, Meads C, Khan KS. The "evil twin syndrome" in chronic pelvic pain: a systematic review of prevalence studies of bladder pain syndrome and endometriosis. Int J Surg. 2013;11(3):233-7.

39. Spinks J, Hollingsworth B. Policy Implications of Complementary and Alternative Medicine Use in Australia: data from the National Health Survey. J Altern Complem Med. 2012;18(4):371-8.

40. Reid R, Steel A, Wardle J, Trubody A, Adams J. Complementary medicine use by the Australian population: a critical mixed studies systematic review of utilisation, perceptions and factors associated with use. BMC Complem Altern Med. 2016;16(1):176.
41. Schwartz ASK, Gross E, Geraedts K, Rauchfuss M, Wölfler MM, Häberlin F, von Orelli S, Eberhard M, Imesch P, Imthurn B, et al. The use of home remedies and complementary health approaches in endometriosis. Reprod Biomed Online. 2019;38(2):260-71.

42. Chen L, Michalsen A. Management of chronic pain using complementary and integrative medicine. BMJ. 2017;357:j1284

43. Simoens S, Dunselman G, Dirksen C, Hummelshoj L, Bokor A, Brandes I, Brodszky V, Canis M, Colombo GL, DeLeire T, et al. The burden of endometriosis: costs and quality of life of women with endometriosis and treated in referral centres. Hum Reprod. 2012;27(5):1292-9.

44. Shafrir AL, Wise LA, Palmer JR, Shuaib ZO, Katuska LM, Vinayak P, Kvaskoff M, Terry KL, Missmer SA. Validity of self-reported endometriosis: a comparison across four cohorts. Hum Reprod. 2021;36(5):1268-78.

\section{Publisher's Note}

Springer Nature remains neutral with regard to jurisdictional claims in published maps and institutional affiliations.

Ready to submit your research? Choose BMC and benefit from

- fast, convenient online submission

- thorough peer review by experienced researchers in your field

- rapid publication on acceptance

- support for research data, including large and complex data types

- gold Open Access which fosters wider collaboration and increased citations

- maximum visibility for your research: over 100M website views per year

At BMC, research is always in progress.

Learn more biomedcentral.com/submissions 